\title{
Taxonomic revision of Australian Amobia Robineau-Desvoidy, 1830 (Sarcophagidae: Miltogramminae): integrating morphology and genetics finds a new species and tackles old problems
}

\author{
Nikolas P. JOHNSTON ${ }^{1, *}$, James F. WALLMAN ${ }^{2}$, Mark DOWTON ${ }^{3}$, \\ Krzysztof SZPILA ${ }^{4} \&$ Thomas PAPE ${ }^{5}$ \\ ${ }^{1,2}$ Centre for Sustainable Ecosystem Solutions, School of Earth, Atmospheric and Life Sciences, \\ University of Wollongong, NSW, Australia. \\ ${ }^{2}$ School of Life Sciences, University of Technology Sydney, NSW, Australia. \\ ${ }^{3}$ Molecular Horizons, School of Chemistry and Molecular Bioscience, \\ University of Wollongong, NSW, Australia. \\ ${ }^{4}$ Department of Ecology and Biogeography, Faculty of Biological and Veterinary Sciences, \\ Nicolaus Copernicus University, Toruń, Poland. \\ ${ }^{5}$ Natural History Museum of Denmark, University of Copenhagen, Denmark. \\ *Corresponding author: npj304@uowmail.edu.au \\ 2Email: james.wallman@uts.edu.au \\ 33mail: mdowton@uow.edu.au \\ ${ }^{4}$ Email: krzysztof.szpila@umk.pl \\ ${ }^{5}$ Email: tpape@snm.ku.dk

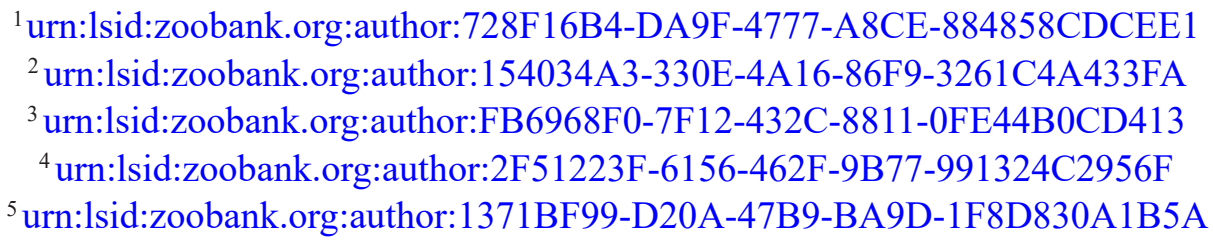

\begin{abstract}
A taxonomic revision of the Australian species of Amobia Robineau-Desvoidy, 1830 (Diptera: Sarcophagidae: Miltogramminae) is completed using an integrated approach combining four molecular loci (three mitochondrial, COI, ND4 and CYTB; one nuclear, EF1 $\alpha$ ) and morphological data. A new species, Amobia (s. str.) serpenta sp. nov., endemic to Australia, is described, and Amobia auriceps (Baranov, 1935) and Amobia burnsi (Malloch, 1930) are re-described. Molecular data are used to reconstruct inter-specific and generic relationships and support morphological species hypotheses. Phylogenetic analysis places all three Australian Amobia species together with Amobia signata (Meigen, 1824) (a Palaearctic species) in a single clade sister to Senotainia Macquart, 1846 (in part), which is in agreement with previous phylogenetic studies of the Miltogramminae. In addition to the description of species and molecular phylogenetics, general host associations for the Australian species of Amobia are discussed and evidence for the synonymisation of A. pelopei (Rondani, 1859) and A. auriceps is refuted.
\end{abstract}

Keywords. Phylogenetics, DNA barcoding, flesh flies, Miltogramminae. 
Johnston N.P., Wallman J.F., Dowton M., Szpila K. \& Pape T. 2020. Taxonomic revision of Australian Amobia Robineau-Desvoidy, 1830(Sarcophagidae:Miltogramminae):integratingmorphologyandgeneticsfindsanewspecies and tackles old problems. European Journal of Taxonomy 722: 75-96. https://doi.org/10.5852/ejt.2020.722.1135

\section{Introduction}

The Miltogramminae (Diptera: Sarcophagidae), accounting for $\sim 20 \%$ of global flesh fly diversity, are characterised by their mostly parasitic life histories. Unlike the many flesh flies that breed in carrion, most members of this subfamily are kleptoparasites in the nests of solitary wasps and bees (Barth 1908; McCorquodale 1986; Spofford et al. 1989; Spofford \& Kurczewski 1990; Polidori et al. 2006). Seven genera are known to occur across the Australasian region (Pape 1996): Aenigmetopia Malloch, 1930 (five spp.; Johnston et al. 2020b), Amobia Robineau-Desvoidy, 1830 (two spp.), Metopia Meigen, 1803 (two spp.) Miltogramma Meigen, 1803 (four spp.), Protomiltogramma Townsend, 1916 (six spp.), Senotainia Macquart, 1846 (one sp.), and, most recently, Macronychia Rondani, 1859 (one sp.; Johnston et al. 2020a).

In an attempt to better understand the diversity of Australian sarcophagids, there has been a recent targeted effort to systematically revise the Australian Miltogramminae and place their constituent genera and species within a global phylogenetic context. This research has been targeted at specific genera, and revisions of Aenigmetopia and Macronychia have already been published (Johnston et al. 2020a, 2020b). This paper focuses on the genus Amobia, within the larger aim of a full treatment of the Australian Miltogramminae.

The genus Amobia is characterised morphologically by 1) the autapomorphic configuration of the anterior margin of the anepimeron, which shows a distinct swelling below the ampulla (Shewell 1987; Pape 1996), and 2) the reduction of the epiphallus, which most likely is apomorphic at the genus level (Pape 1996; Buenaventura et al. 2020). Additional diagnostic features, which are also found in other miltogrammine genera, are the relatively high number $(>5)$ of fine, hair-like proclinate fronto-orbital setae; the antennal insertion at or below the midpoint of the eye, and the claws longer than the fifth tarsomere in both sexes (Pape 1996). Similarly, species of Amobia can be characterised by the hosts of their inquilinous larvae, which are predominantly mud daubers and potter wasps (Hymenoptera: Sphecidae, Crabronidae; Vespidae: Eumeninae) (Itino 1988; Downing 1996; Coville 2000; Fateryga \& Kovblyuk 2014).

The world fauna of Amobia consisted of 13 species prior to this study, with the highest species diversity in the Nearctic region (six spp.) and modest numbers known from the Afrotropical (two spp.), Australasian (two spp.), Neotropical (three spp.), Oriental (four spp.) and Palaearctic (four spp.) regions. Amobia comprises two subgenera: 1) Sarcomacronychia Townsend, 1892 restricted to the Nearctic and Neotropical regions and characterised by red-coloured terminalia, the male abdominal tergite 6 setose and free from syntergosternite $7+8$, fewer than 10 proclinate fronto-orbital setae and posterior spiracles of the puparium not recessed*, and 2) the widespread Amobia (s. str.), characterised by brown terminalia, male abdominal tergite 6 bare* and fused to syntergosternite $7+8^{*}, 10$ or more proclinate fronto-orbital setae* and the posterior spiracles of the puparium recessed ( $(*)=$ possible synapomorphies; Zumpt 1961; Draber-Mońko 1966; Pape 1996; Zhang et al. 2011).

The evolutionary relationships between Amobia and the other miltogrammine genera have been hypothesised based on morphology (Rohdendorf 1967; Verves 1989) and more recently also molecular data (Piwczyński et al. 2017; Buenaventura et al. 2020). The molecular phylogenies of Piwczyński et al. (2017) and Buenaventura et al. (2020) are generally congruent and placed Amobia as sister to a part of Senotainia in a clade also containing Macronychia* and Oebalia Robineau-Desvoidy, 1863, thereby 
rendering Senotainia paraphyletic, with Amobia signata (Meigen, 1824) splitting Senotainia tricuspis (Meigen, 1838)* and Senotainia albifrons (Rondani, 1859) from Senotainia conica (Fallén, 1810). ('*' = included in the phylogeny of Piwczyński et al. 2017 only.) The early morphology-based evolutionary hypotheses favoured a tribal classification of the Miltogramminae, with Amobia first placed within the tribe Senotainiini along with Aenigmetopia, Chorezmomyia Rohdendorf, 1935, Eumacronychia Townsend, 1892, Senotainia and Taxigramma Perris, 1852, and later moved into its own monotypic tribe Amobiini (Verves 1989). A tribal classification has since been abandoned (Pape 1996; Piwczyński et al. 2017; Buenaventura et al. 2020).

The Australian fauna of Amobia has so far received little attention. Until now, the genus was represented in Australia by two species: Amobia auriceps (Baranov, 1935) (which is also distributed throughout the broader Australasian/Oceanian and Oriental regions) and the endemic Amobia burnsi (Malloch, 1930). This paper adds to this body of knowledge through the taxonomic revision of Australian Amobia, describing a new endemic species, providing new characters for the separation of species, and providing extensive photographic documentation of the adult morphology and terminalia. Molecular data (four loci: COI, CYTB, ND4 and EF1 $\alpha$ ) are utilized to support morphological species hypotheses, allow further insight into the taxonomic distinctiveness of this genus and, through phylogenetics, place the Australian Amobia within the framework provided by Piwczyński et al. (2017).

\section{Materials and methods}

\section{Morphology}

Specimens were collected during several research expeditions across Australia during the summer months of 2016-2018. All specimens were collected individually using a hand net, killed in ethyl acetate vapour and either preserved in ethanol the same day or pinned for taxonomic identification. Photodocumentation of the adult morphology and male terminalia of A. auriceps and A. burnsi was completed using a BK lab system (Visionary Digital, VA, USA), with photographic stacking performed with Zerene Stacker (Zerene Systems, LLC, Richland, WA, USA). Photographs of dissected male terminalia were taken from preparations in glycerol. Photo-documentation of $A$. serpenta sp. nov. was completed using a Leica DFC295 digital camera (3M pixel) mounted on a Leica MZ16a stereo-microscope and analysed using Leica Application Suite ver. 3.8.0 (Leica Microsystems Limited, Germany).

For preparation of SEM images, male terminalia in glycerol were rinsed in demineralised water, dehydrated in $96 \%$ ethanol, air-dried, mounted on adhesive electrical tape attached to aluminium stubs, coated with $\sim 100 \mathrm{~nm}$ of platinum/palladium and studied using a JEOL JSM-6335 F scanning electron microscope (JEOL, Tokyo, Japan). Due to the availability of only two male specimens of $A$. serpenta sp. nov., it was decided to avoid dissection of this species and to document and describe the relevant structures based on extended terminalia of the holotype.

For documentation of adult morphology, specimens were studied under a Leica MZ75 microscope (Leica Microsystems Limited) in conjunction with the photographs and SEM images. Terminology for morphological characters follows Cumming \& Wood (2017), with additional characters relevant to Miltogramminae obtained from Pape (1996). For label data, Australian states and territories are denoted by standard abbreviations (ACT: Australian Capital Territory, NSW: New South Wales, NT: Northern Territory, QLD: Queensland, SA: South Australia, WA: Western Australia), additional information provided verbatim in square brackets after the label data, and repository by institutional abbreviation in parentheses. 


\section{Specimen repository abbreviations}

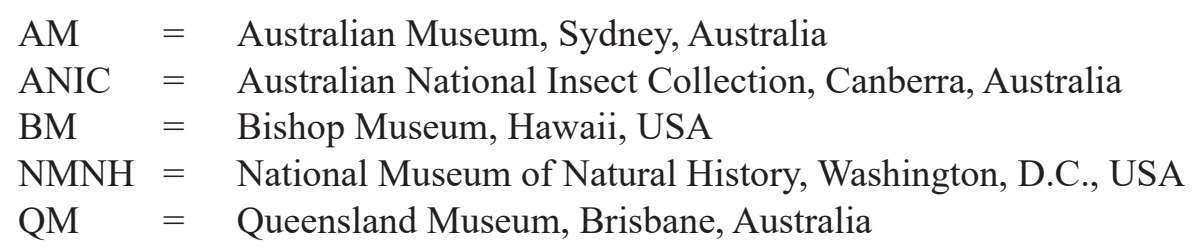

\section{DNA extraction, amplification and sequencing}

Molecular analysis was employed to support the morphological species hypotheses and phylogenetically place the Australian Amobia among the global Miltogramminae. DNA extraction, amplification and sequencing methods followed Meiklejohn et al. (2011) and Piwczyński et al. (2017). In short: the total genomic DNA was extracted from a single leg of four specimens of A. auriceps, two of A. burnsi and a single specimen of $A$. serpenta sp. nov. using the salting-out method described by Aljanabi \& Martinez (1997) (see Supplementary file 1 for a full list of taxa and specimens used in the molecular analysis, including accession numbers for genetic data originally sequenced by Piwczyński et al. 2017) and stored at $4{ }^{\circ} \mathrm{C}$ prior to amplification. The four genes used by Piwczyński et al. (2017) for their global miltogrammine phylogeny, COI, CYTB, ND4 and EF1 $\alpha$, were also amplified for our Amobia specimens. Temperature cycling conditions for amplification followed the general structure of one cycle at $94^{\circ} \mathrm{C}$ for $2 \mathrm{~min} ; 35$ cycles at $95^{\circ} \mathrm{C}$ for $30 \mathrm{~s} ; 45-65^{\circ} \mathrm{C}$ gradient for $15 \mathrm{~s} ; 72^{\circ} \mathrm{C}$ for $30 \mathrm{~s}$; and one cycle at $72^{\circ} \mathrm{C}$ for $5 \mathrm{~min}$. Annealing temperature optimisation for gene fragments was as follows: $50.6^{\circ} \mathrm{C}$ for COI, $51{ }^{\circ} \mathrm{C}$ for $\mathrm{CYTB}, 45^{\circ} \mathrm{C}$ for $\mathrm{ND} 4$ and $53^{\circ} \mathrm{C}$ for $\mathrm{EF} 1 \alpha$. The extension time for $\mathrm{EF} 1 \alpha$ was increased from $30 \mathrm{~s}$ to $45 \mathrm{~s}$ to account for the $>1 \mathrm{~kb}$ length of the target sequence. Primer pairs used for gene amplification and their relevant sequences are available in Table 1.

Amplification success was confirmed by resolving PCR products through agarose gel electrophoresis. Prior to sequencing, $5 \mu \mathrm{l}$ aliquots of samples were treated with $2 \mu \mathrm{l}$ of $2 \mathrm{x}$ diluted ExoSAPIT Express ${ }^{\circledR}$ (Applied Biosystems, Foster City, CA, USA), following the manufacturer's instructions, in order to digest unincorporated dNTPs and primers. ExoSAPIT Express ${ }^{\circledR}$ treated products were then sequenced using ABIPRISM ${ }^{\circledR}$ BigDye $^{\mathrm{TM}}$ Terminator ver. 3.1 Sequencing Kit (Applied Biosystems, Foster City, CA, USA). The sequencing products were separated using an ABI 3130xl Genetic Analyser (Applied Biosystems, Foster City, CA, USA).

Sequence electropherograms were edited using ChromasPro version 1.33 (Technelysium, South Brisbane, QLD, Australia; available online at www.technelysium.com.au/wp/chromaspro) and confirmed to be of miltogrammine origin by cross-checking species identity by submission to the Basic Local Alignment Search Tool (BLAST; National Center for Biotechnology Information, Bethesda, MD, USA; available online at blast.ncbi.nlm.nih.gov).

\section{Automatic barcode gap discovery for species delimitation}

Prior to phylogenetic analysis, COI sequences for all extracted Amobia (seven in total: four A. auriceps, two $A$. burnsi and a single $A$. serpenta sp. nov) were aligned using MUSCLE (Edgar 2004; MUSCLE parameters: gap opening penalty $=-400$, gap extension penalty $=0$, Clustering Method $=$ UPGMB, Maximum diagonal length =24) in Geneious Prime 2019.0.3 (https://www.geneious.com) and submitted to the Automatic Barcode Gap Discovery online analysis tool (ABGD; Puillandre et al. 2012, available from: https://bioinfo.mnhn.fr/abi/public/abgd/). Analysis was completed using following Puillandre et al. (2012) using the Kimura two parameters model (Kimura 1980; default parameters). The number of input sequences used was lower than recommended for ABGD (three-five sequences per species); the developers (Puillandre et al. 2012) note that having less than the recommended number of sequences can result in the inability to accurately detect the "barcode gap". As such, this study did not use the prior 
Table 1. Primer sequences used for DNA amplification.

\begin{tabular}{|c|c|c|c|}
\hline Primer name & Direction & Target gene & Sequence $5^{\prime}-3^{\prime}$ \\
\hline LCO1490-L & Forward & $\mathrm{COI}$ & $\begin{array}{l}\text { 5'-GGTCWACWAATCATAAAGATA } \\
\text { TTG-3' }\end{array}$ \\
\hline HCO2198-L & Reverse & $\mathrm{COI}$ & $\begin{array}{l}\text { 5'-RAAACTTCWGGRTGWCCAAAR } \\
\text { AATCA-3' }\end{array}$ \\
\hline CB-J-10933 & Forward & CYTB & $\begin{array}{l}\text { 5'-TATGTTTTACCTTGAGGACAAA } \\
\text { TATC-3' }\end{array}$ \\
\hline TSI-N-11683 & Reverse & CYTB & $\begin{array}{l}\text { 5'-AAATTCTATCTTATGTTTTCAA } \\
\text { AАC-3' }\end{array}$ \\
\hline N4-N-9194 & Forward & ND4 & $\begin{array}{l}\text { 5'-ATTTTTTGAAAGAAGTTTAAT } \\
\text { TCC-3' }\end{array}$ \\
\hline N4-J-8502 & Reverse & ND4 & $\begin{array}{l}\text { 5'-GTTGGAGGAGCTGCTATATTA } \\
\text { G-3' }\end{array}$ \\
\hline $\mathrm{EF} 1 \_21 \mathrm{~F}$ & Reverse & $\mathrm{EF} 1 \alpha$ & 5'-TGAGCGYGARCGTGGTATCAC-3' \\
\hline $\mathrm{rcM} 4$ & Reverse & $\mathrm{EF} 1 \alpha$ & 5'-ACAGCVACKGTYTGYCTCATRTC-3' \\
\hline
\end{tabular}

intraspecific divergence (barcode gap) as the basis for species delimitation, but rather the K2P distance matrix generated by ABGD was used to calculate inter- and intraspecific distance between species. The distance between COI barcodes was then used to support morphological species hypotheses.

\section{Alignment and phylogenetic analysis (Fig. 1)}

Following ABGD analysis, a phylogeny was prepared to determine the position of Australian Amobia species among the global miltogrammines. Sequence data from the phylogeny of Piwczyński et al. (2017) for COI, CYTB, ND4 and EF1 $\alpha$ were obtained from GenBank (taxa list: Supplementary file 2), concatenated, and aligned along with the new sequences of Amobia using the MUSCLE algorithm in Geneious Prime 2019.0.3 (https://www.geneious.com). Aligned sequences were then submitted for analysis in PartitionFinder2 (Lanfear et al. 2016), which simultaneously determines the best partitioning scheme and model. Partitioning by gene and codon position (a total of 12 partitions) produced the highest corrected Akaike Information Criterion (AICc) value and was used in Maximum Likelihood (ML) and Bayesian inference (BI) analyses. The model with the highest calculated AICc was GTR+I+G; this model was utilised for all partitions in the BI analysis. The creator of RAxML recommends not estimating invariant sites in RAxML; as such, the GTR $+\mathrm{G}$ model was used for all partitions in the ML analysis. ML analysis was performed in RAxML ver. 8.0 (Stamatakis 2014) (GTR+G model, 1000 bootstrap iterations; Miller et al. 2010) and BI analysis was performed in MrBayes ver. 3.2.6 utilising the BEAGLE library. Four simultaneous Bayesian analyses were completed, each utilising four Markov Chain Monte Carlo $(\mathrm{MCMC})$ chains (three heated, one cold; temperature default $=0.1)$. Each chain was run for 20 million generations, sampling every 2000 generations (for a total of 40,000 samples). All priors for the analysis remained at their default settings. To confirm run success and effective sampling of the priors, MCMC convergence was confirmed by examining effective sample size (ESS) and potential scale reduction factors (PRSF) (which were confirmed to be greater than 100 and $\sim 1$, respectively). A consensus tree was then prepared from the resultant trees with the first $25 \%$ of all trees discarded as burn-in. Paritionfinder2, RAxML and MrBayes analyses were performed within the online CIPRES platform (Miller et al. 2010).

A final tree graphic summarising both analyses (ML and $\mathrm{BI}$ ) was produced using FigTree (ver. 1.4.3; Rambaut 2010) and edited in Adobe Illustrator ${ }^{\circledR}$ (available from https://www.adobe.com/au/products/illustrator). 


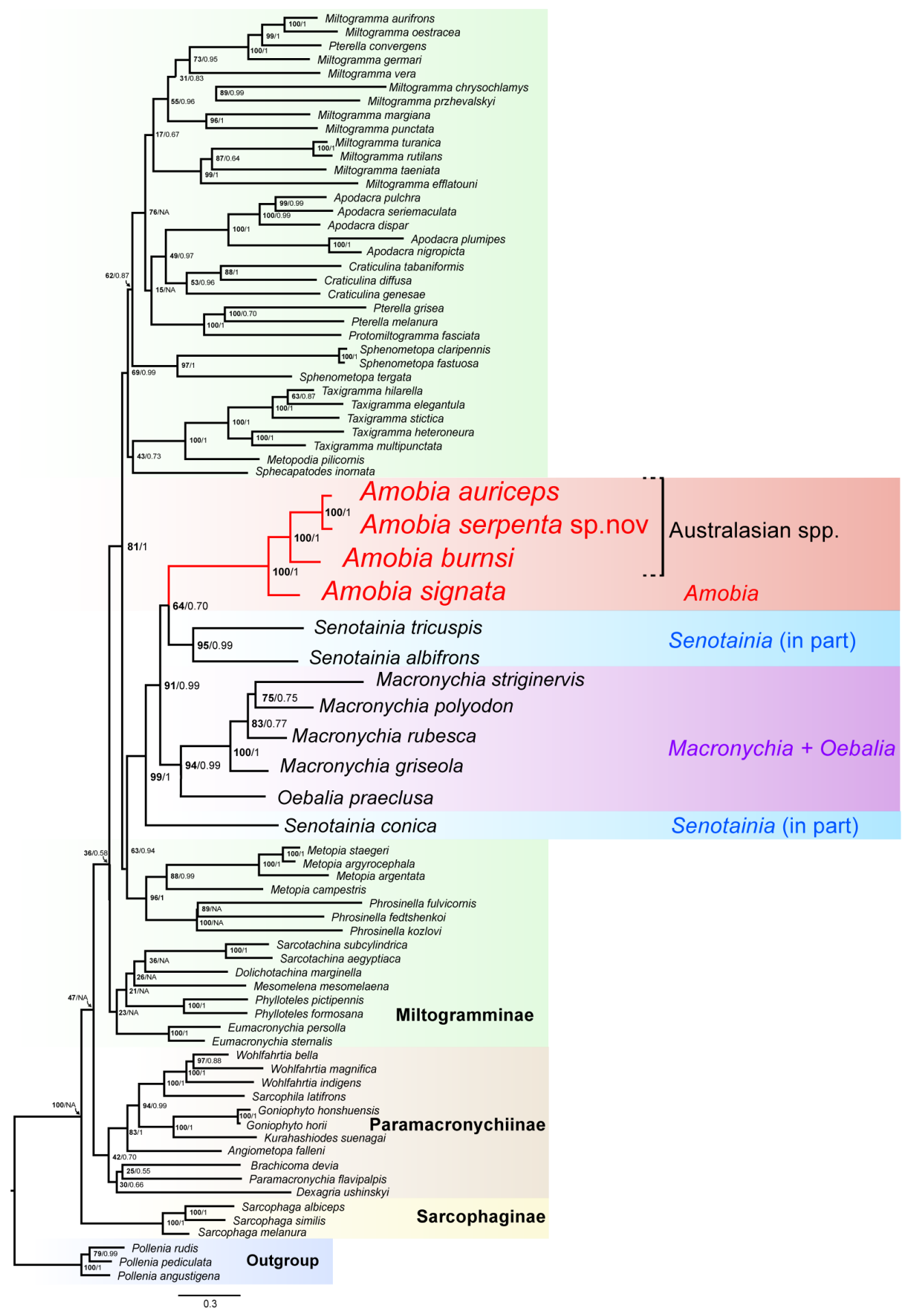

Fig. 1. Maximum likelihood phylogenetic tree indicating the placement of Amobia among the global Miltogramminae, inferred from COI, CYTB, ND4 and EF1 $\alpha$ sequence data. With the exception of the three newly sequenced Australian Amobia and Macronychia rubesca, data was acquired from Piwczyński et al. (2017). Node support values are shown for both maximum likelihood analysis (bootstrap support, 1000 iterations; in bold font) and Bayesian analysis (posterior probability, 40 million generations), 'NA' indicates nodes resolved that were not resolved by the Bayesian analysis. Branch length scale $=0.3$ nucleotide substitutions per site (calculated by the GTR $+\mathrm{G}$ nucleotide substitution model). 


\section{Results}

\section{Taxonomy}

Class Insecta Linnaeus, 1758

Order Diptera Linnaeus, 1758

Family Sarcophagidae Macquart, 1834

Subfamily Miltogramminae Lioy, 1864

Genus Amobia Robineau-Desvoidy, 1830

Amobia (s. str.) auriceps (Baranov, 1935)

Figs $2-3$

Pachyophthalmus auriceps Baranov, 1935: 558.

\section{Diagnosis}

The males of this species can be distinguished from the other two Australian species of Amobia by the combination of dull yellow microtomentum present on the fronto-orbital and parafacial plates, brown basicosta and bare proepisternum (the latter feature, however, is variable in the two other Australian species and therefore not by itself fully diagnostic).

\section{Material examined}

Lectotype (designated by Sabrosky \& Crosskey 1970: 430)

SRI LANKA • ô; Colombo; 6 Feb. 1931; N. Baranov leg.; NMNM.

\section{Other material}

AUSTRALIA • 1 đ̧; QLD, Gordonvale; 1919; J.F. Illingworth leg.; [label indicates 'collected ex

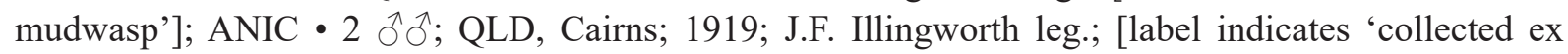
mudwasp']; BM); • 6 क $\circ$; QLD, Cairns; 1919; J.F. Illingworth leg.; [label indicates 'collected ex mudwasp']; BM • 1 q; QLD, Gordonvale; 1919; J.F. Illingworth leg.; [label indicates 'collected ex mudwasp']; BM • 1 क; QLD, Gap Creek Reserve; 6 Dec. 2016; Johnston, Butterworth and Wallman leg.; ANIC • 1 क ; QLD, Bowling Green National Park; 9 Jan. 2017; Johnston, Pape and Wallman leg.; ANIC - 1 क; NT, Track to Lost City, Litchfield National Park; 10 Nov. 2017; Johnston, Wallman and Szpila leg.; ANIC • 1 \%; QLD, 26 km W 'Fairview'; 24 Apr. 1989; G. Daniels and A. Daniels leg.; QM - 1 o; QLD, Mt Abbott; 12 Apr. 1997; C.J. Burwell leg.; QM • 1 क; QLD, Redlands, Hillard Creek; 20 Jan. 2009; QM Party leg.; [label indicates collected in 'scribbly gum open forest']; QM • 1 क; QLD, Teddington Weir, Maryborough; 13 Nov. 1994; G. Daniels and A. Daniels leg.; [label indicates collected in 'vine forest margin']; QM.

\section{Redescription}

SizE. 6.0-9.0 $\mathrm{mm}(\mathrm{n}=19)$.

\section{Male}

HeAD (Fig. 2B, D, G). With dull yellow microtomentum on fronto-orbital and parafacial plates; frontal stripe dark brown and concave; fronto-orbital plate setose with a single distinct row (at least 15 setae) and additional unordered fine fronto-orbital setulae; third aristomere tapered, fine and hair-like distally, black and twice as long as first flagellomere; pedicel and scape setose; first flagellomere black and 1.5 $\times$ the length of pedicel; gena and postgena grey with black setae; genal groove present, dark brown; vibrissa located midway between tip of first flagellomere and mouth margin; numerous supra-vibrissal 


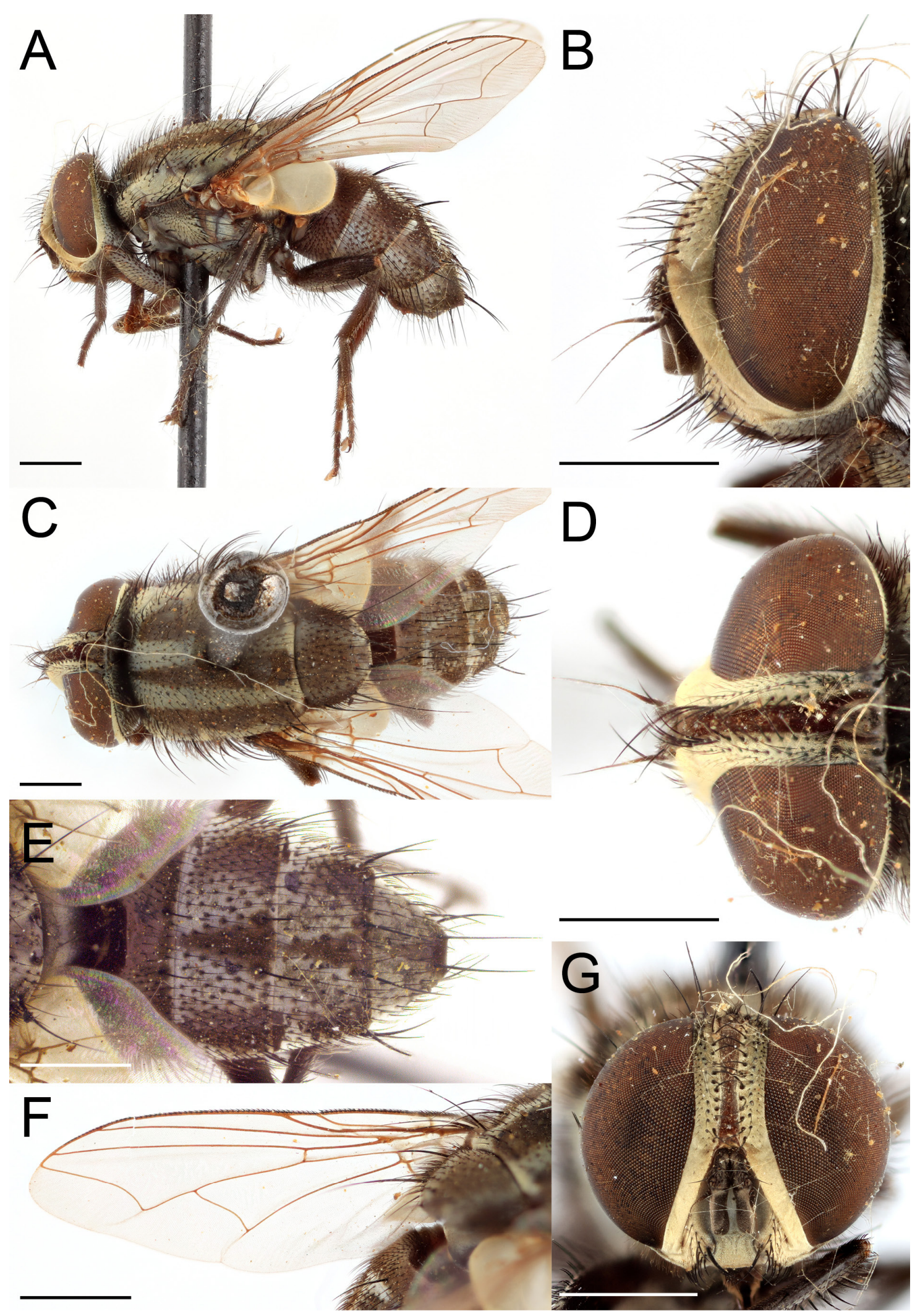

Fig. 2. Amobia auriceps (Baranov, 1935), วิ, QLD, Cairns, 1919, J.F. Illingworth leg. (BM). A. Habitus, lateral view. B. Head, lateral view. C. Habitus, dorsal view. D. Head, dorsal view. E. Abdomen, dorsal view. F. Left wing dorsal view. G. Head anterior view. Scale bars: $1 \mathrm{~mm}$. 
setae; vibrissal setae and supra-vibrissal setae present in two rows, inner row strong and ordered, outer row weak and unordered.

ThORAX (Fig. 2A, C). Grey with dull yellow-brown microtomentum (visible only at certain angles); one major median and two major lateral stripes; major stripes ending at anterior margin of scutellum; scutellum with some darkening on lateral margin; two notopleural setae with additional finer setae on entire surface; proepisternum bare; katepisternal setae $1+1$.

WING (Fig. 2F). Hyaline; vein $\mathrm{R}_{1}$ bare; vein $\mathrm{R}_{4+5}$ with several setae at base; cell $\mathrm{r}_{4+5}$ open; tegula black; basicosta, brown.

LeGS (Fig. 2A).Black; claws of fore tarsus slightly longer than tarsomere 5; mid tibia with one anterodorsal and one ventral seta.

AbDomen (Fig. 2A, C, E). T1+2 dark brown; setose and with two distinct median marginal setae; T3 setose, with two distinct median marginal setae and additional finer setae along entire posterior margin; T4-T5: setose with marginal setae on entire posterior margin; black ground colour most clearly visible towards the posterior margin; dull grey microtomentum present (occupying the majority of each tergite); three distinct black spots (two lateral and one median) on T3 and T4; T5 with only median black spot.

Male terminalia (Fig. 3A-B). Cercus sickle-shaped in lateral view and narrowest in middle portion (middle portion $\sim 20 \%$ of cercus length); setose dorsally; cerci straight in posterior view, separated by a small gap between tips of cercal prongs; surstylus straight in lateral view, shorter than cercus; curved medially towards cercus in posterior view; phallus blunt with small spines on distal lobe.

\section{Female}

As male except microtomentum generally paler, especially on fronto-orbital plate where it appears silvery grey. The authors have chosen not to redescribe the female genitalia.
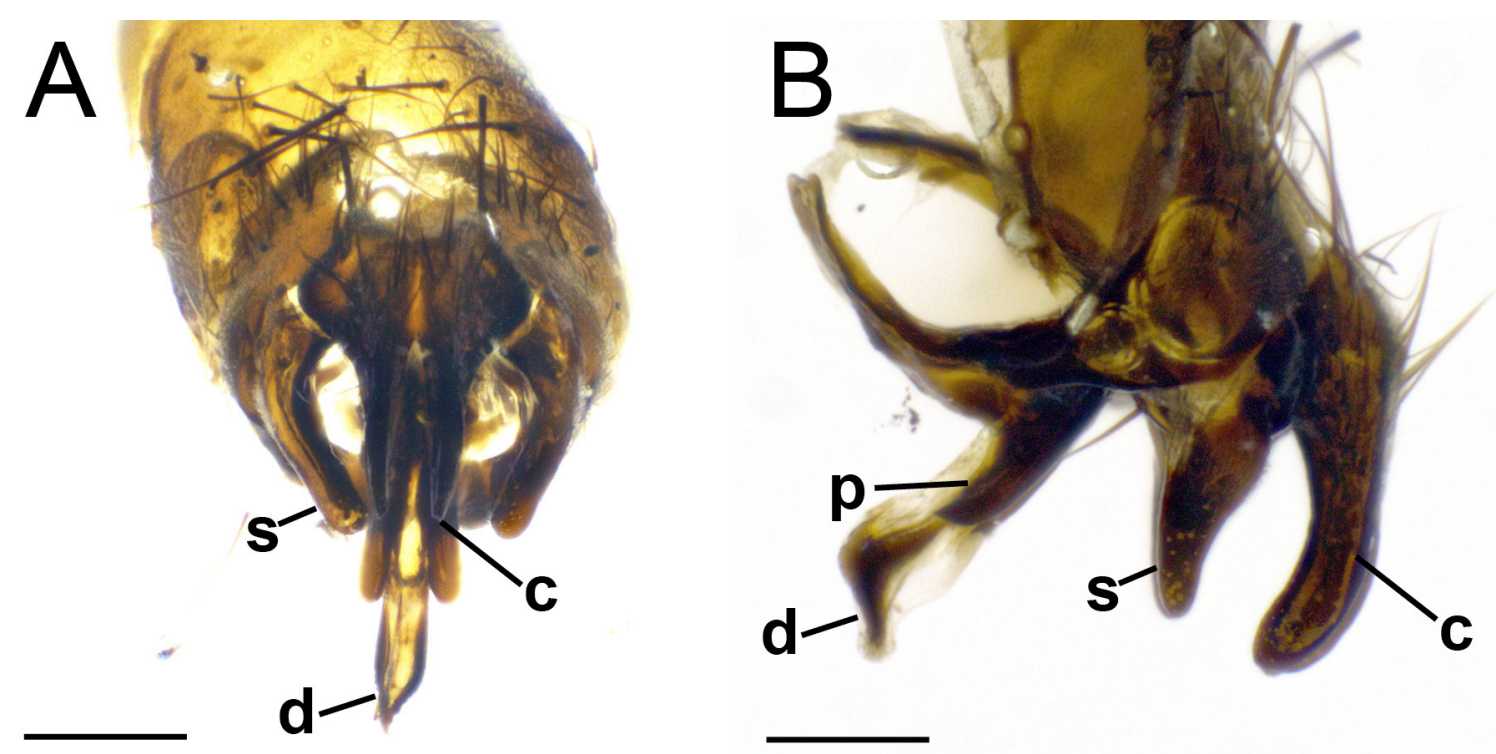

Fig. 3. Amobia auriceps (Baranov, 1935), male terminalia, QLD, Cairns, 1919, J.F. Illingworth leg. (BM). A. Epandrium, cerci, surstyli and phallus, posterior view. B. Epandrium, cerci, surstyli, phallus and pre-gonite, lateral view. Abbreviations: $\mathrm{c}=$ cercus; $\mathrm{d}=$ distal lobe of phallus; $\mathrm{s}=$ surstylus; $\mathrm{p}=$ pregonite. Scale bars: $100 \mu \mathrm{m}$. 


\section{Biology}

Label data confirm an association with 'mudwasps', probably family Sphecidae.

\section{Distribution}

Australasia/Oceania - Australia (NT, QLD), Hawaiian Is., Papua New Guinea. Oriental - India, Laos, Malaysia, Philippines, Sri Lanka, Taiwan.

\section{Remarks}

There has been some contention as to the validity of A. auriceps. Kurahashi (1974) considered A. auriceps to be conspecific with Amobia pelopei (Rondani, 1859), a species known only from the western Palaearctic region. He did, however, note differences in the shape of the cerci and surstyli, as well as in the colouration of the basicosta. Verves (1979) and Pape (1996), by comparison, considered A. pelopei and A. auriceps as distinct species, separated through the morphology of the terminalia and by the colouration of the fronto-orbital plates. This study is in agreement with Verves (1979) and Pape (1996). It should be noted that perhaps the most reliable character for the separation of these species is the shape of the cercus in lateral view, which is gradually tapering in A. pelopei (Kurahashi, 1974: fig. 1) and distinctly narrowed in the middle in A. auriceps (Fig. 3B).

Amobia (s. str.) burnsi (Malloch, 1930)

Figs $4-5$

Austrometopia burnsi Malloch, 1930: 438.

\section{Material examined}

Holotype

AUSTRALIA • đ̇; QLD, Meringa; 28 Jun. 1926; A.N. Burns leg.; [label indicates 'Parasitic on Eumenid']; ANIC.

\section{Other material}

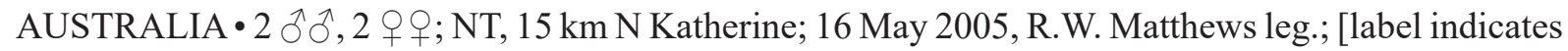
'Reared: ex. Nest of Delta latreillei (Saussure)']; ANIC • 1 \%; QLD, Lockhart R; Rev. Hint leg.; ANIC - 1 §̊; NSW, North Head, Sydney Harbour; 14 Feb. 1978; G. Daniels leg.; AM • 19; [neither locality, date nor collector; label indicates 'parasitic on Sceliphron laetum']; QM.

\section{Diagnosis}

Males of this species can be distinguished from the other two Australian species of Amobia by the combination of distinct bright golden microtomentum on the fronto-orbital as well as parafacial plates and yellow-brown basicosta.

\section{Redescription}

Size. 8.0-10.0 $\mathrm{mm}(\mathrm{n}=7)$.

\section{Male}

HEAD (Fig. 4B, D, G). With golden microtomentum on fronto-orbital and parafacial plates; frontal stripe dark brown and concave; fronto-orbital plate setose with two distinct rows of setae, one row of frontal setae ( $>10$ setae) and one row of proclinate fronto-orbital setae ( $>10$ setae) and additional fine frontoorbital setulae, setal rows ending before lunule; third aristomere broad at base and tapering to fine hairlike tip distally, black and twice as long as first flagellomere; pedicel and scape setose; first flagellomere 


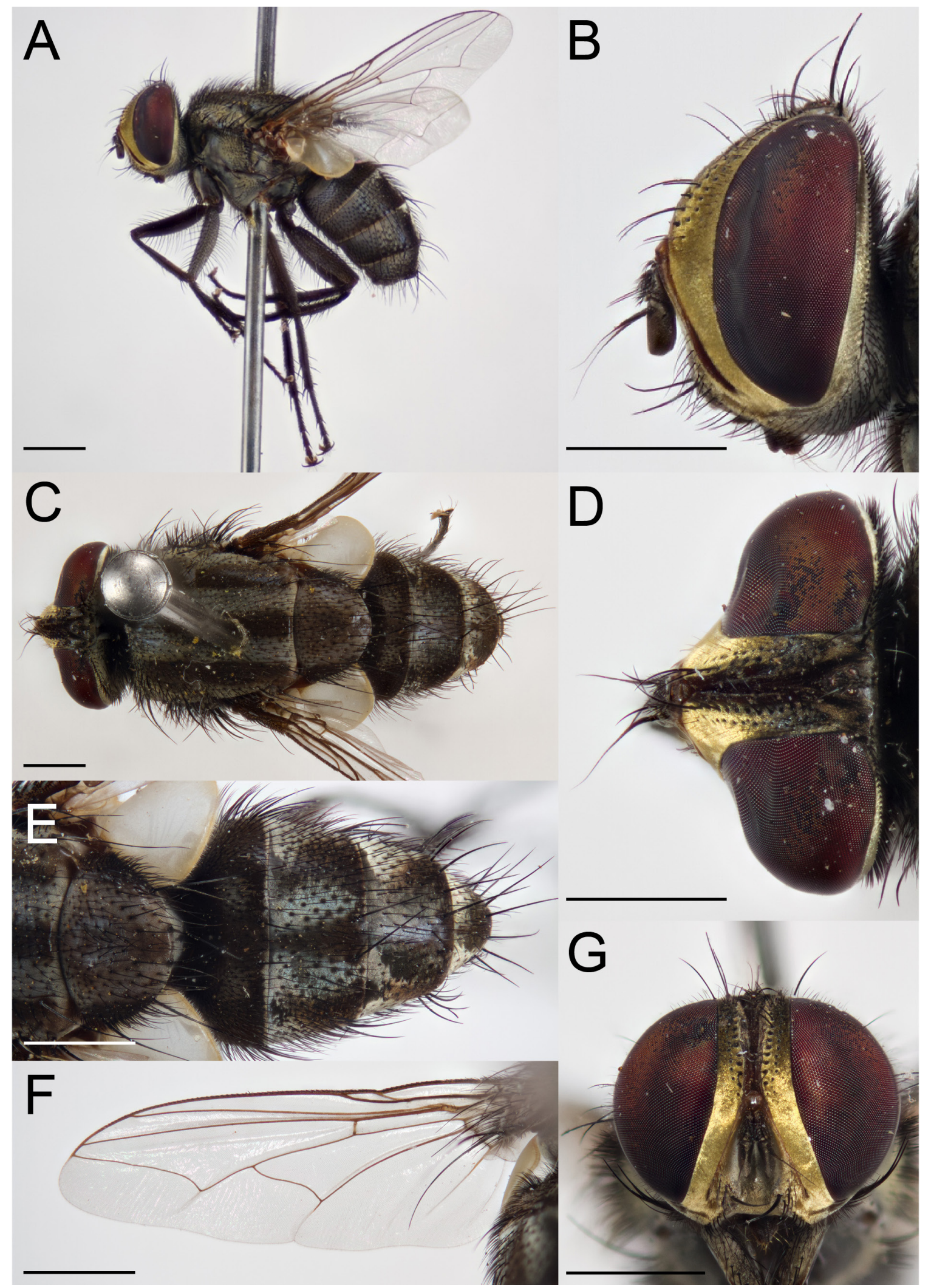

Fig. 4. Amobia burnsi (Malloch, 1930), ổ, NSW, North Head, Sydney Harbour, 14 Feb. 1978, G. Daniels leg. (AM) A. Habitus, lateral view. B. Head, lateral view. C. Habitus, dorsal view. D. Head, dorsal view. E. Abdomen, dorsal view. F. Left wing, dorsal view. G. Head, anterior view. Scale bars: $1 \mathrm{~mm}$. 
black and slightly longer than pedicel; parafacial plate with fine setae near facial ridge in multiple disordered rows; gena and postgena grey with black setae; genal groove present, dark brown; vibrissa located midway between tip of first flagellomere and mouth margin; numerous supra-vibrissal setae present in two rows, inner row strong and ordered, outer row weak and unordered.

Thorax (Fig. 4A, C). Grey with some dull yellow microtomentum anteriorly; one major median, two major lateral and two faint minor lateral stripes (located mediad to lateral major stripes and approximately one quarter of their width); major stripes ending at anterior margin of scutellum; minor stripes ending just anterior to suture; scutellum with some darkening on lateral margins; two notopleural setae, with numerous additional fine setae; proepisternum setose; katepisternal setae $1+1$.

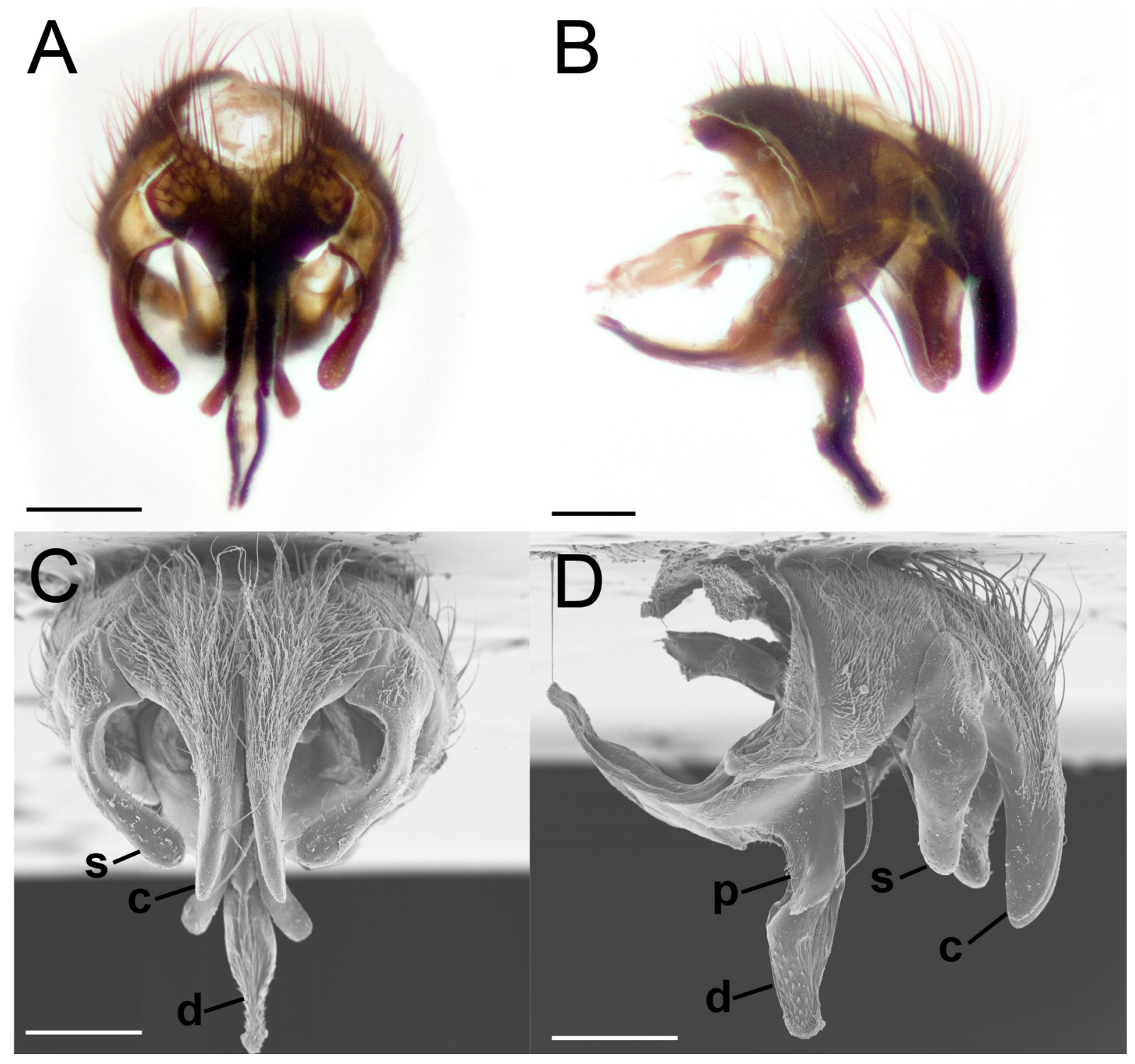

Fig. 5. Amobia burnsi (Malloch, 1930), male terminalia, NT, $15 \mathrm{~km} \mathrm{~N}$ Katherine, 16 May 2005, R.W. Matthews leg (ANIC). A. Epandrium, cerci, surstyli and phallus, posterior view. B. Epandrium, cerci, surstyli, phallus and pre-gonite, lateral view. C. SEM image of epandrium, gonites, cerci and surstyli, posterior view. D. SEM image of epandrium, gonites, phallus, cerci and surstyli, lateral view. Abbreviations: $\mathrm{c}=$ cercus; $\mathrm{d}=$ distal lobe of phallus; $\mathrm{s}=$ surstylus; $\mathrm{p}=$ pre-gonite. Scale bars: $100 \mu \mathrm{m}$. 
WING (Fig. 4F). Hyaline; vein $\mathrm{R}_{1}$ bare; vein $\mathrm{R}_{4+5}$ with several setae at base; cell $\mathrm{r}_{4+5}$ open; tegula black; basicosta light yellow brown.

LEGS (Fig. 4A). Black; claws of fore tarsus slightly longer than tarsomere 5; pulvilli slightly shorter than fore tarsal claws; mid tibia with one anteroventral and one anterodorsal seta.

Aвdomen (Fig. 4A, C, E). T1+2 black; setose, with two distinct median marginal setae; T3-T5: setose, with two distinct median marginal setae and additional finer setae along entire posterior margin of each tergite; black ground colour most clearly visible towards posterior margin; dull grey microtomentum present (occupying almost the entirety of each tergite); three distinct black spots (two lateral and one median) on T3 and T4; T5 with only one median black spot.

MaLe terminalia (Fig. 5A-D). Cercus sickle-shaped in lateral view, broad at base and pointed apically; densely setose dorsally; cerci diverging in posterior view with a weak curve away from one another; surstylus straight in lateral view, shorter than the cerci; in posterior view, surstyli slightly curved medially towards cerci; phallus blunt with small spines on distal lobe, swollen apically.

\section{Female}

As male except with generally paler microtomentum, especially on head where it appears dull grey. The authors have chosen not to redescribe the female genitalia.

\section{Biology}

Label data indicate [klepto]parasitism of wasps of the families Vespidae (Delta latreillei (Saussure, 1852)) and Sphecidae (Sceliphron laetum (Smith, 1856)).

\section{Distribution}

Australasia - Australia (NSW, NT, QLD, WA).

\section{Remarks}

Amobia burnsi was described in the monotypic genus Austrometopia Malloch, 1930. This classification has since been rejected as it rendered the genus Amobia paraphyletic (Kurahashi 1970; Pape 1996). Pape (1996) specified that, in the genus Amobia, the fore-tarsal claws are longer than the fifth tarsomere in both sexes; however, this was not observed in females of $A$. burnsi examined in this study, and as such may not be a character of all Amobia.

It should be noted that proepisternal setosity has been observed to be variable in this species and as such cannot be used to diagnose it.

Amobia (s. str.) serpenta sp. nov. urn:1sid:zoobank.org:act:884490D3-8113-4F75-B4BD-E0E88209BC88

Figs 6-7

\section{Diagnosis}

Males of this species can be distinguished from the other two Australian members of Amobia by the unique dual head colouration (silver microtomentum on the fronto-orbital and parafacial plates, and golden microtomentum on upper mouth edge, gena and postgena) in combination with the area of golden microtomentum on the notopleuron. 


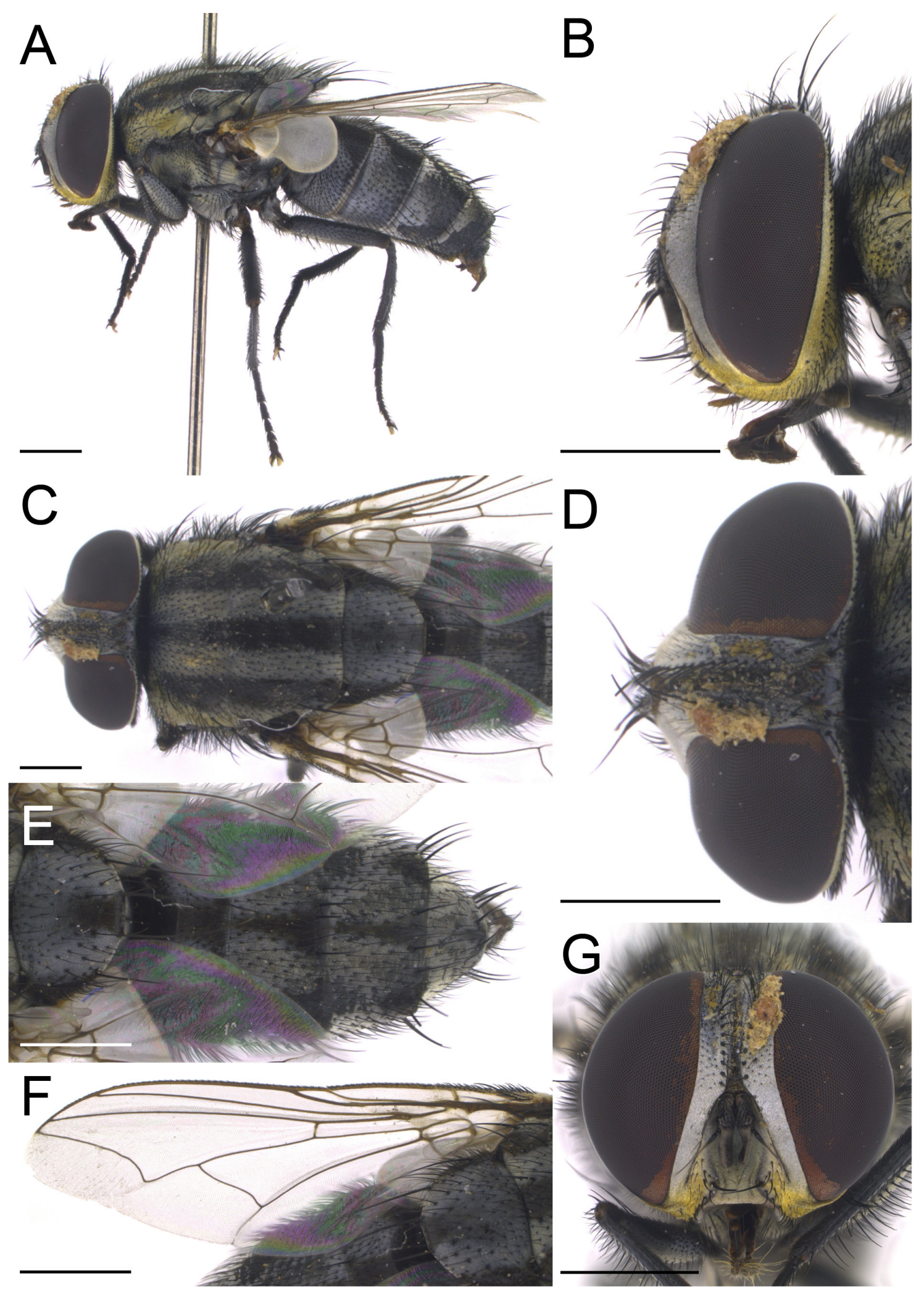

Fig. 6. Amobia serpenta sp. nov., holotype, $\widehat{\jmath}$, NT, Serpentine Gorge, West MacDonnell National Park, 13 Nov. 2017, Johnston, Wallman and Szpila leg. (ANIC). A. Habitus, lateral view. B. Head, lateral view. C. Habitus, dorsal view. D. Head, dorsal view. E. Abdomen, dorsal view. F. Left wing, dorsal view. G. Head, anterior view. Scale bars: $1 \mathrm{~mm}$. 


\section{Etymology}

The species epithet 'serpenta', which should be treated as a noun in apposition, refers to Serpentine Gorge, the type locality of this species.

\section{Type material}

\section{Holotype}

AUSTRALIA - ơ; NT, Serpentine Gorge, West MacDonnell National Park; 13 Nov. 2017; Johnston, Wallman \& Szpila leg.; ANIC.

\section{Paratypes}

AUSTRALIA • 1 đ; WA, 2 miles S of Dempster; 19 Oct. 1970; D.H. Colless leg.; ANIC • 1 q; NT, Alice Springs; 21-27 Sep. 1972; R.W. Matthews leg.; ANIC • 1 \%; QLD, Birdsville Track; Sep. 1936; A. Muncham leg.; [label indicates: 'reared from clay nest of mason wasp (Eumenidae)']; ANIC $\bullet 1$; WA, White Spring Ruins NE of Wittenoom; 16 Aug. 1970; P. Ferrar leg.; ANIC • 1 क; SA, Nullarbor; 25 Oct. 1958; E.F. Riek leg.; ANIC • 1 क; WA, Carson Escarpment; 15 Aug. 1975; I.F.B. Common and M.S. Upton leg.; ANIC.

\section{Description}

Size. $6-9 \mathrm{~mm}(\mathrm{n}=7)$.

\section{Male}

HEAD (Fig. 6B, D, G). Grey with silver microtomentum on fronto-orbital and parafacial plates, and golden microtomentum on upper mouth edge, gena and postgena; frontal stripe black and distinctly concave; fronto-orbital plate setose with one distinct row of fronto-orbital setae ( $>10$ setae) and additional unordered fine fronto-orbital setulae; setal rows ending at height of lunule; third aristomere broad in basal third then tapering to a fine hair-like tip distally, black and $2 \times$ length of the first flagellomere; pedicel and scape setose; first flagellomere black and slightly longer than pedicel; parafacial plate with fine setae near facial ridge, in multiple disordered rows; gena yellow and postgena light grey with black

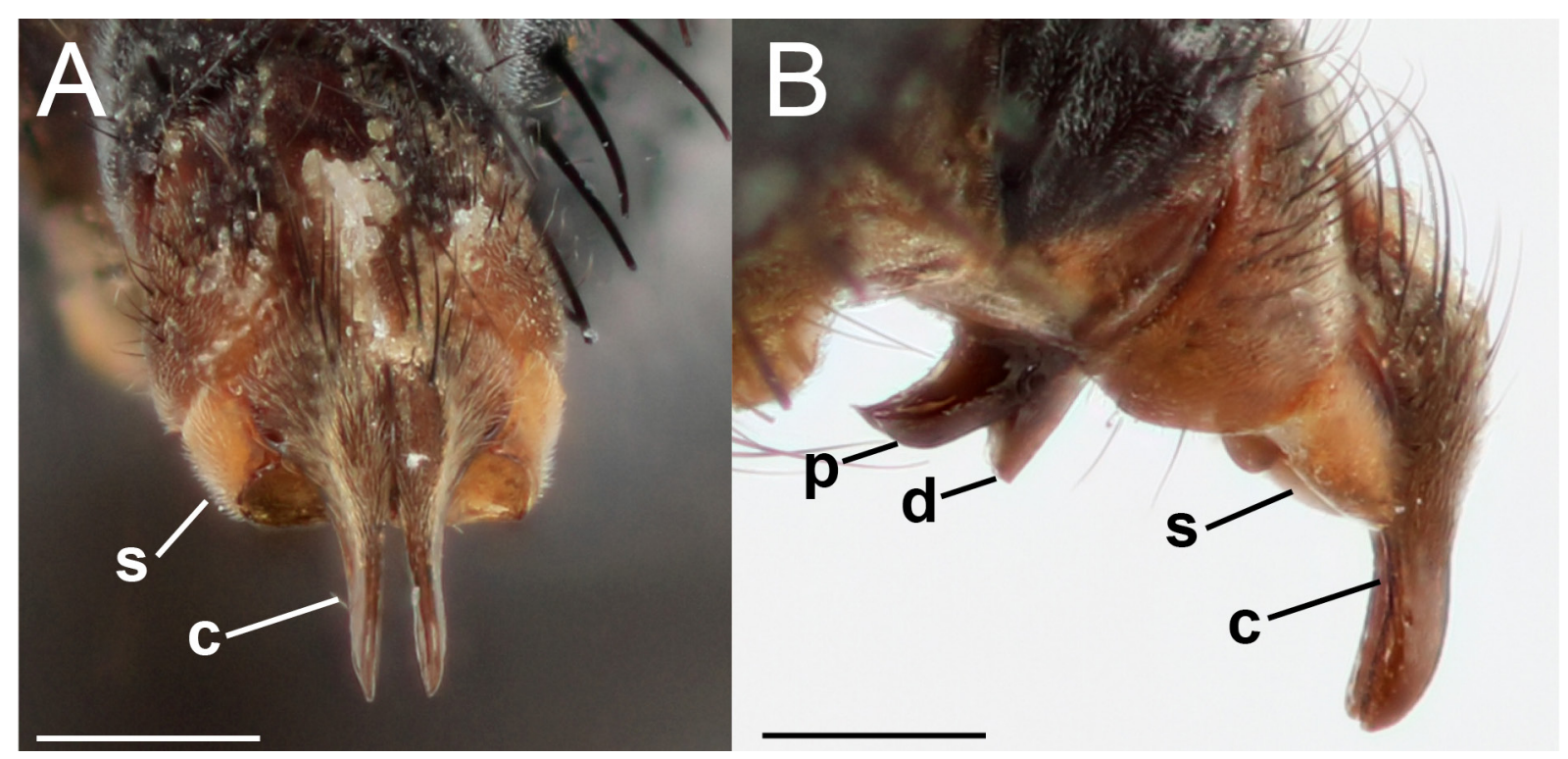

Fig. 7. Amobia serpenta sp. nov., holotype, male terminalia, NT, Serpentine Gorge, West MacDonnell National Park, 13 Nov. 2017, Johnston, Wallman and Szpila leg. (ANIC). A. Epandrium, cerci, surstyli, and phallus, posterior view. B. Epandrium, cerci, surstyli, phallus and pre-gonites, lateral view. Abbreviations: $\mathrm{c}=$ cerci; $\mathrm{d}=$ distal lobe (broken); $\mathrm{s}=$ surstylus; $\mathrm{p}=$ pre-gonite. Scale bars: $100 \mu \mathrm{m}$. 
setae; genal groove present, dark brown; vibrissa located midway between tip of first flagellomere and mouth margin; numerous supra-vibrissal setae.

Thorax (Fig. 6A, C). Grey with golden microtomentum, particularly antero-dorsally and forming distinct patch on notopleuron; one major median, two major lateral and two faint minor lateral stripes (minor stripes placed medially to major stripes and approximately one quarter of their width); major stripes continuing full length of scutellum, minor stripes ending just anterior to suture; two notopleural setae, with numerous additional fine setae on entire notopleural surface; proepisternum bare or setose; katepisternal setae $1+1$.

WING (Fig. 6F). Hyaline; vein $\mathrm{R}_{1}$ bare; vein $\mathrm{R}_{4+5}$ with several setae at base; cell $\mathrm{r}_{4+5}$ open; tegula black; basicosta yellow white.

LeGs (Fig. 6A). Black; claws of fore tarsus slightly longer than tarsomere 5; pulvilli as long as fore tarsal claws; mid tibia with one anteroventral and one anterodorsal seta.

Aвdomen (Fig. 6A, C, E). T1+2: black; setose and with two distinct median marginal setae; T3-T5: setose, each with one pair of distinct median marginal setae; T5 with additional marginal setae along entire posterior surface; black ground colour most clearly visible towards posterior margin; dull grey microtomentum present, occupying entirety of tergites; three distinct black stripes (two lateral and one median) on T3; T4 with median stripe and two lateral spots; T5 with only one median black spot.

MaLe terminalia (Fig. 7A-B). Cercus (lateral view) sickle-shaped broad at base and tapered; setose on dorsal surface; posteriorly, cerci slightly diverging apically; surstylus shorter than cercus, single lobed on posterior margin; posteriorly, surstyli curved medially.

\section{Female}

As male except for slightly darker microtomentum on the fronto-orbital plate, appearing dull yellow. Parafacial plate, gena and post gena remain golden and distinctly different to fronto-orbital plate. The authors have chosen not to describe the female genitalia.

\section{Biology}

The holotype of this species was collected on a hilltop, perching on an exposed rock. Paratype label data indicate an association with vespid wasps (Vespidae: Eumeninae).

\section{Distribution}

Australasia - Australia (NT, QLD, SA, WA).

\section{Remarks}

Amobia serpenta sp. nov. is placed within the subgenus Amobia s. str. due to the brown coloured terminalia and more than 10 proclinate fronto-orbital setae (Zumpt 1961; Pape 1996). Due to the limited number of male specimens (two), it was decided to avoid dissection of the male terminalia and rather to describe the extended male terminalia of the pinned holotype. For this reason, and as the phallus was broken off completely in the holotype, only the cerci and surstyli could be accurately described. 


\section{Key to males of Australian Amobia}

1. Fronto-orbital and parafacial plates with silver microtomentum, upper mouthedge and gena with golden microtomentum (Fig. 6B, D, G); notopleuron with a distinct area of golden microtomentum (Fig. 6A)

A. (s. str.) serpenta sp. nov.

- Fronto-orbital plate and parafacial plate both with golden or dull yellow microtomentum; gena with grey or golden microtomentum (Figs 2B, D, G, 4B, D, G); notopleuron without golden microtomentum (Fig. 2A-B)

2. Fronto-orbital plate with dull yellow microtomentum (Fig. 2A-B, G); basicosta brown; male terminalia: cerci in lateral view broad in basal and distal 0.4 with distinct narrowing in middle 0.2 (Fig. 3B); in posterior view cerci straight and not curved away from one another (Fig. 3A) A. (s. str.) auriceps (Baranov, 1935)

- Fronto-orbital plate with bright golden microtomentum (Fig. 4A-B, G); basicosta yellow-brown; male terminalia: cerci in lateral view gradually tapering from base to tip (Fig. 5B, D); in posterior view cerci weakly curved away from one another (Fig. 5A, C)....A. (s. str.) burnsi (Malloch, 1930)

\section{Phylogenetic analysis}

\section{Molecular analysis}

BLAST searches of COI sequences from A. auriceps, A. burnsi and A. serpenta sp. nov. all showed the closest matches with a previously submitted sequence erroneously identified as a Protomiltogramma sp. (>96\% similarity; JN964698). Fortunately, the original voucher specimen could be retrieved from the University of Wollongong Diptera collection and re-identified as A. auriceps. The sequences of Amobia were also a good match with a previously identified Amobia signata originally sequenced for the phylogeny of Piwczyński et al. (2017) (> 92\% similarity; KY749709).

Representative COI sequences from each species were analysed using the ABGD online tool. Preliminary analysis of COI data supported the morphological species hypothesis, despite the low number of input sequences. All three species were molecularly distinct, with mean inter- and intraspecific distance calculated as $4.00 \%$ and $0.24 \%$, respectively (calculated using Kimura two parameters model; Kimura 1980). The greatest between-species distance was observed between $A$. burnsi and A. auriceps (mean interspecific distance $=4.85 \%, \mathrm{n}=8$ ). The next greatest distance was between $A$. auriceps and $A$. serpenta sp. nov. (mean interspecific distance $=4.64 \%, \mathrm{n}=2$ ). The smallest distance was between $A$. burnsi and $A$. serpenta sp. nov. (mean interspecific distance $=2.08 \%, \mathrm{n}=4$ ), this distance is $\sim 10 \times$ higher than the mean intraspecific distance for all Amobia species $(0.24 \%)$ and $13 \times$ higher than the mean intraspecific distance calculated for A. burnsi $(0.15 \%)$.

\section{Phylogenetic reconstruction}

A Maximum Likelihood phylogeny was reconstructed based on the new sequences obtained from Australian Amobia (three concatenated sequences, one for each of the three species) and the sequence data of Piwczyński et al. (2017) (Fig. 1). The Bayesian inference phylogeny was generally concordant with the Maximum Likelihood phylogeny (Fig. 1; only support values shown).

The phylogeny recovered the genus Amobia as monophyletic. In terms of interspecific relationships, $A$. auriceps emerged as sister to $A$. serpenta sp. nov. (ML: bootstrap support $=100 \%$, BI: posterior probability $=1$ ) and $A$. auriceps $+A$. serpenta sp. nov. were sister to $A$. burnsi (ML: bootstrap support $=100 \%$, BI: posterior probability $=1)$. Amobia signata was sister to all other Amobia species (ML: bootstrap support $=100 \%, \mathrm{BI}$ : posterior probability $=1$ ). 
The intergeneric relationships presented in both the ML and BI phylogenetic hypotheses agreed with Piwczyński et al. (2017), with all Amobia resolved as a single clade sister to Senotainia (in part: Senotainia albifrons + Senotainia tricuspis) (ML: 64\% bootstrap support, BI: posterior probability = 0.70) and with Amobia + Senotainia (in part) sister to Macronychia + Oebalia (ML: $91 \%$ bootstrap support, BI: posterior probability = 0.99). The Amobia, Senotainia, Macronychia and Oebalia cluster was sister to Metopia, Phrosinella Robineau-Desvoidy, 1863 and the rest of the higher miltogrammines (Piwczyński et al. 2017; ML: 63\% bootstrap support, BI: posterior probability = 0.94).

\section{Discussion}

\section{Species diagnosis}

This study is the first to attempt to integrate morphological and molecular data to establish a strongly supported species hypothesis for the Australian Amobia. Morphology supported a three-species hypothesis, with the description of a new species, A. serpenta sp. nov., and the re-description of both A. auriceps and A. burnsi. The most diagnostic characters for the Australasian species of Amobia were colouration of the fronto-orbital plate and colouration of the basicosta, characters also known to be diagnostic for species of this genus in the Oriental, Nearctic and Palaearctic regions (Kurahashi 1974; Pape 1996). Unlike other regions, the presence and colouration of the microtomentum on the notopleuron was also found to be diagnostic in Australian Amobia.

\section{DNA barcoding and molecular phylogenetics}

Despite the low number of input sequences, preliminary ABGD analysis provided evidence supporting all three Australian species of Amobia identified by morphology. Between-species genetic distance was $\sim 17 \times$ higher than within-species genetic distance $(4.00 \%$ compared to $0.23 \%)$. The most closely related COI barcodes were observed between $A$. burnsi and $A$. serpenta sp. nov. (2.08\% interspecific distance) however this was still $\sim 10 \times$ higher than the mean intraspecific distance calculated for all species.

Both the Maximum Likelihood and Bayesian phylogenetic analyses clustered all three Australian species of Amobia together with A. signata. Within this Amobia clade A. serpenta sp. nov. + A. auriceps is sister to $A$. burnsi. Other than providing insight into the taxonomy and phylogeny of the Australian fauna of Amobia, our results agree with the intergeneric relationships presented by Piwczyński et al. (2017); Amobia is sister to Senotainia (in part; S. tricuspis and S. albifrons) then Amobia + Senotainia (in part) is sister to Macronychia. Thus, the addition of additional Amobia species in this analysis provides additional support to the previous phylogenetic hypotheses for the subfamily Miltogramminae.

\section{Rejection of synonymisation of $A$. auriceps (Baranov, 1935) and A. pelopei (Rondani, 1859)}

This revision supports the separation of $A$. auriceps and A. pelopei as distinct species. Verves (1979) and Pape (1996) separated A. pelopei and A. auriceps through the colouration of the fronto-orbital plates (A. pelopei with silver microtomentum, A. auriceps with yellow gold microtomentum). Verves (1979) additionally suggested that the terminalia of $A$. auriceps could be distinguished from those of $A$. pelopei by the terminally angular cerci and an apically dilated phallus. We follow Verves (1979) and Pape (1996) in considering $A$. auriceps and A. pelopei as separate species and confirm the dull yellow colouration of the fronto-orbital plate in $A$. auriceps as an important character for the separation of these species.

In addition to the morphological evidence for separation, the barcode library of Australian Amobia prepared in this study will help to either support or refute the separation of A. auriceps and A. pelopei once molecular data have been obtained for $A$. pelopei. 
All Australian representatives identified by Meiklejohn et al. (2012) as A. pelopei were examined as part of this study and are re-identified as $A$. burnsi through the diagnostic combination of golden frontoorbitals and male terminalia. The COI barcode fragment of these specimens also matched to A. burnsi.

\section{Wasp associations and the distribution of species of Amobia}

Label data from Australasian species provides evidence for the association of $A$. burnsi and A. serpenta sp. nov. with vespid wasps (recorded from the nests, or closely following 'potter' wasps; subfamily Eumeninae), and A. auriceps and A. burnsi with sphecid wasps (recorded from 'mud' wasps; family Sphecidae). This is generally consistent with previously recorded host associations for this genus in other parts of the world. Species of Amobia have been recorded as kleptoparasites of sphecid and vespid wasps in the Nearctic, Oriental and Palaearctic regions (Fye 1965; Itino 1988; Wcislo 1996; Fateryga \& Kovblyuk 2014) and of vespids and crabronid wasps in the Neotropical region (Freeman \& Jayasingh 1975; Buys 2007; Nascimento \& Garófalo 2014). No records are available that associate any Australasian species with wasps of the family Crabronidae.

While known from locations hundreds of kilometres from the nearest city or town (e.g., Litchfield NP, Northern Territory), Australia's species of Amobia also appear to occur with their hosts in urban environments. Amobia burnsi and A. auriceps species have been observed usurping wasp nests located in tunnels, overpasses and attached to buildings (pers. obs.). Australian Amobia should be expected to occur wherever suitable wasp hosts are found.

\section{Acknowledgements}

The authors gratefully acknowledge the Australian National Insect Collection, Australian Museum, Bishop Museum, Queensland Museum and National Museum of Natural History and for the provision of pinned specimens. The authors' gratitude is also extended to David Yeates and Olivia Evangelista (Australian National Insect Collection) for their kind assistance in providing access to photographic facilities for documentation of several specimens in this study, Nathan Butterworth and Blake Dawson (University of Wollongong) for their help collecting fresh specimens, and Tracey Gibson (also University of Wollongong) for her assistance with the genetic analysis. Finally, we thank the Australian Biological Resources Study (grant RF215-59) and the Polish National Science Centre (grant 2015/17/B/ NZ8/02453) for their financial support of this project, and Daniel Whitmore and an anonymous reviewer for their contributions to the revision of this manuscript.

\section{References}

Aljanabi S.M. \& Martinez I. 1997. Universal and rapid salt-extraction of high quality genomic DNA for PCR-based techniques. Nucleic Acids Research 25: 4692-4693. https://doi.org/10.1093/nar/25.22.4692

Baranov N. 1935. Neue paläarktische und orientalische Raupenfliegen (Diptera, Tachinidae). Veterinarski Arhiv 5: 550-560.

Barth G.P. 1908. The nesting of Anacrabro ocellatus Pack. Bulletin of the Wisconsin Natural History Society 6: 147-153.

Buenaventura E., Szpila K., Cassel B.K., Wiegmann B.M. \& Pape T. 2020. Anchored hybrid enrichment challenges the traditional classification of flesh flies (Diptera: Sarcophagidae). Systematic Entomology 45: 281-301. https://doi.org/10.1111/syen.12395

Buys S.C. 2007. Comparative study of the nesting behaviour of Tachysphex inconspicuus (Kirby) (Hymenoptera: Crabronidae) in two locations in southeast Brazil. Neotropical Entomology 36: 327-330. https://doi.org/10.1590/S1519-566X2007000300001 
Coville R.E. 2000. Observations on the nesting biology and behavior of Trypoxylon (Trypargilum) vagulum (Hymenoptera: Sphecidae) in Costa Rica. Pan-Pacific Entomologist 76: 28-48.

Cumming J.M. \& Wood D.M. 2017. 3. Adult morphology and terminology. In: Kirk-Spriggs A.H. \& Sinclair B.J. (eds) Manual of Afrotropical Diptera. Volume 1. Introductory Chapters and Keys to Diptera Families. Suricata 4: 89-133. South African National Biodiversity Institute, Pretoria.

Downing H. 1996. Methods of escape for both fly parasites and wasps from the clustered pipes of Trypoxylon politum nests (Hymenoptera: Sphecidae). Journal of the Kansas Entomological Society 68: 473-476.

Draber-Mońko A. 1966. Bemerkungen über die paläarktischen Arten der Gattung Pachyophthalmus B.B. (Diptera, Sarcophagidae). Polskie Pismo Entomologiczne 36: 395-405.

Edgar R.C. 2004. MUSCLE: multiple sequence alignment with high accuracy and high throughput. Nucleic Acids Research 32: 1792-1797. https://doi.org/10.1093/nar/gkh340

Fateryga A.V. \& Kovblyuk M.M. 2014. Nesting ecology of the wasp Sceliphron destillatorium (Illiger, 1807) (Hymenoptera, Sphecidae) in the Crimea. Entomological Review 94: 330-336. https://doi.org/10.1134/S001387381403004X

Freeman B.E. \& Jayasingh D.B. 1975. Population dynamics of Pachodynerus nasidens (Hymenoptera) in Jamaica. Oikos 26: 86-91. https://doi.org/10.2307/3543282

Fye R.E. 1965. The biology of the Vespidae, Pompilidae, and Sphecidae (Hymenoptera) from trap nests in Northwestern Ontario. The Canadian Entomologist 97: 716-744. https://doi.org/10.4039/Ent97716-7

Itino T. 1988. The spatial patterns of parasitism of eumenid wasps, Anterhynchium flavomarginatum and Orancistrocerus drewseni by the miltogrammine fly Amobia distorta. Population Ecology 30: 1-12. https://doi.org/10.1007/BF02512598

Johnston N.P., Wallman J.F., Pape T. \& Whitmore D. 2020a. Macronychia (Diptera: Sarcophagidae) goes cosmopolitan: description and molecular delineation of the first Australasian species. Austral Entomology 59: 292-301. https://doi.org/10.1111/aen.12447

Johnston N.P., Wallman J.F., Szpila K. \& Pape T. 2020b. An enigma no more: an integrated taxonomic revision of Aenigmetopia Malloch reveals novel phylogenetic placement and four new species (Diptera : Sarcophagidae : Miltogramminae). Invertebrate Systematics 34: 519-534.

https://doi.org/10.1071/is19051

Kimura M. 1980. A simple method for estimating evolutionary rates of base substitutions through comparative studies of nucleotide sequences. Journal of Molecular Evolution 16: 111-120. https://doi.org/10.1007/BF01731581

Kurahashi H. 1970. Studies on the calypterate muscoid flies from Japan VII. Revision of the subfamily Miltogramminae (Diptera Sarcophagidae). Kontyû 38: 93-116.

Kurahashi H. 1974. Note on the genus Amobia from the Indo-Australian area with description of a new species (Diptera: Sarcophagidae). Pacific Insects 16: 57-60.

Lanfear R., Senfeld T., Frandsen P.B., Wright A.M. \& Calcott B. 2016. PartitionFinder 2: New methods for selecting partitioned models of evolution for molecular and morphological phylogenetic analyses. Molecular Biology and Evolution 34: 772-773. https://doi.org/10.1093/molbev/msw260

Malloch J.R. 1930. Notes on Australian Diptera. XXV. Proceedings of the Linnean Society of New South Wales 55: 429-450. 
McCorquodale D.B. 1986. Digger wasp (Hymenoptera: Sphecidae) provisioning flights as a defence against a nest parasite, Senotainia trilineata (Diptera: Sarcophagidae). Canadian Journal of Zoology 64: 1620-1627. https://doi.org/10.1139/z86-244

Meiklejohn K.A., Wallman J.F. \& Dowton M. 2011. DNA-based identification of forensically important Australian Sarcophagidae (Diptera). International Journal of Legal Medicine 125: 27-32. https://doi.org/10.1007/s00414-009-0395-y

Meiklejohn K.A., Dowton M. \& Wallman J.F. 2012. Notes on the distribution of 31 species of Sarcophagidae (Diptera) in Australia, including new records in Australia for eight species. Transactions of the Royal Society of South Australia 136: 56-64. https://doi.org/10.1080/03721426.2012.10887163

Miller M.A., Pfeiffer W. \& Schwartz T. 2010. Creating the CIPRES Science Gateway for inference of large phylogenetic trees. In: 2010 Gateway Computing Environments Workshop (GCE) New Orleans: 1-8. https://doi.org/10.1109/GCE.2010.5676129

Nascimento A.L.O. \& Garófalo C.A. 2014. Trap nesting solitary wasps (Hymenoptera: Aculeata) in an insular landscape: mortality rates for immature wasps, parasitism, and sex ratios. Sociobiology 61: $207-217$

Pape T. 1996. Catalogue of the Sarcophagidae of the world (Insecta: Diptera). Memoirs on Entomology, International 8: 1-557.

Piwczyński M., Pape T., Deja-Sikora E., Sikora M., Akbarzadeh K. \& Szpila K. 2017. Molecular phylogeny of Miltogramminae (Diptera: Sarcophagidae): Implications for classification, systematics and evolution of larval feeding strategies. Molecular Phylogenetics and Evolution 116: 49-60. https://doi.org/10.1016/j.ympev.2017.07.001

Polidori C., Federici M., Papadia C. \& Andrietti F. 2006. Nest sharing and provisioning activity of females of the digger wasp, Cerceris rubida (Hymenoptera, Crabronidae). Italian Journal of Zoology 73: 55-65. https://doi.org/10.1080/11250000500502079

Puillandre N., Lambert A., Brouillet S. \& Achaz G. 2012. ABGD, Automatic Barcode Gap Discovery for primary species delimitation. Molecular Ecology 21: 1864-1877. https://doi.org/10.1111/j.1365-294X.2011.05239.x

Rambaut A. 2010. FigTree v1.3.1. Institute of Evolutionary Biology, University of Edinburgh, Edinburgh. Available from http://tree.bio.ed.ac.uk/software/figtree/ [accessed 12 Oct. 2020].

Rohdendorf B.B. 1967. The directions of historical development of Sarcophagidae (Diptera). Trudy Paleontologicheskogo Instituta Akademii Nauk SSSR 116: 1-92.

Sabrosky C.W. \& Crosskey R.W. 1970. The type-material of Muscidae, Calliphoridae, and Sarcophagidae described by N. Baranov (Diptera). Proceedings of the Entomological Society of Washington 72: 425436.

Shewell G.E. 1987. Sarcophagidae. In: McAlpine J.F. (ed.) Manual of Nearctic Diptera, Vol. 2. 28: 1159-1186. Research Branch, Agriculture Canada Monograph, Ottawa.

Spofford M.G. \& Kurczewski F.E. 1990. Comparative larvipositional behaviours and cleptoparasitic frequencies of Nearctic species of Miltogrammini (Diptera: Sarcophagidae). Journal of Natural History 24: 731-755. https://doi.org/10.1080/00222939000770511

Spofford M.G., Kurczewski F.E. \& Downes W.L. 1989. Nearctic species of Miltogrammini (Diptera: Sarcophagidae) associated with species of Aculeata (Hymenoptera: Vespoidea, Pompiloidea, Sphecoidea, Apoidea). Journal of the Kansas Entomological Society 62: 254-267. 
Stamatakis A. 2014. RAxML version 8: a tool for phylogenetic analysis and post-analysis of large phylogenies. Bioinformatics 30: 1312-1313. https://doi.org/10.1093/bioinformatics/btu033

Verves Y.G. 1979. Review of the subfamily Miltogrammatinae (Diptera, Sarcophagidae) of Sri Lanka. Entomologicheskoe óbozrenie 58: 883-897.

Verves Y.G. 1989. The phylogenetic systematics of the Miltogramminae flies (Diptera, Sarcophagidae) of the World. Japanese Journal of Medical Science and Biology 42: 111-126.

https://doi.org/10.7883/yoken1952.42.111

Wcislo W.T. 1996. Parasitism rates in relation to nest site in bees and wasps (Hymenoptera: Apoidea). Journal of Insect Behavior 9 643-656. https://doi.org/10.1007/BF02213885

Zhang B.-S., Jia F.-L. \& Pape T. 2011. A revisional study of Amobia Robineau-Desvoidy from mainland China (Diptera, Sarcophagidae, Miltogrammatinae). Acta Zootaxonomica Sinica 36: 616-619.

Zumpt F. 1961. Calliphoridae (Diptera Cyclorrhapha). Part III: Miltogramminae. Exploration du Parc national Albert, Mission G.F. de Witte 98: 1-137.

Manuscript received: 22 December 2019

Manuscript accepted: 27 August 2020

Published on: 28 October 2020

Topic editor: Nesrine Akkari

Desk editor: Natacha Beau

Printed versions of all papers are also deposited in the libraries of the institutes that are members of the EJT consortium: Muséum national d'histoire naturelle, Paris, France; Meise Botanic Garden, Belgium; Royal Museum for Central Africa, Tervuren, Belgium; Royal Belgian Institute of Natural Sciences, Brussels, Belgium; Natural History Museum of Denmark, Copenhagen, Denmark; Naturalis Biodiversity Center, Leiden, the Netherlands; Museo Nacional de Ciencias Naturales-CSIC, Madrid, Spain; Real Jardín Botánico de Madrid CSIC, Spain; Zoological Research Museum Alexander Koenig, Bonn, Germany; National Museum, Prague, Czech Republic.

Supplementary file 1. Vouchers, citations and accession numbers for sequences included in the phylogenetic analysis.

https://doi.org/10.5852/ejt.2020.722.1135.3003

Supplementary file 2. Bayesian inference phylogenetic tree displaying the placement of Amobia among the global Miltogramminae, inferred from COI, CYTB, ND4 and EF1 $\alpha$ sequence data https://doi.org/10.5852/ejt.2020.722.1135.3005 